
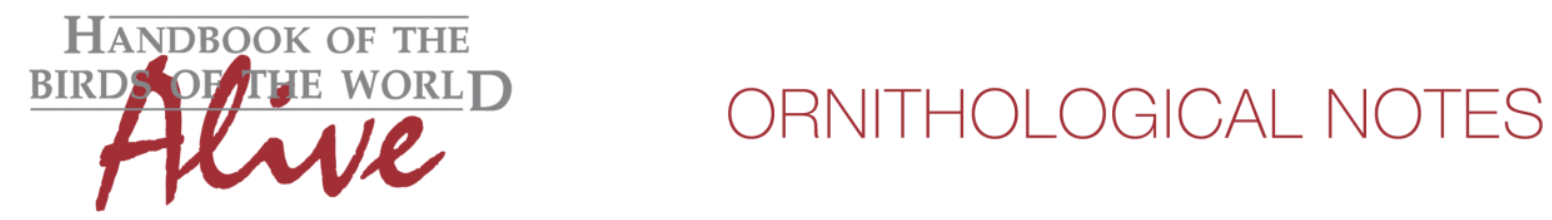

\title{
Notes on the vocalizations of Mountain Elaenia (Elaenia frantzii)
}

Peter Boesman

In the following we briefly analyze and compare voice of the different races of Mountain Elaenia (Elaenia frantzii). We also try to quantify the extent of any vocal differences using the criteria proposed by Tobias et al. (2010), as a support for taxonomic review.

We have made use of sound recordings available on-line from Xeno Canto (XC) and Macaulay Library (ML).

Members of the genus Elaenia have a dawn song and several day-time 'calls'. Dawn song is usually the most complex vocalization, often quite rhythmic, and very constant over the entire range of the species (a true suboscine!). Unlike some other Tyrant-flycatchers (e.g. Zimmerius genus), every species has a very characteristic dawn-song, which thus is an excellent indicator for taxonomic decisions. It is only in recent years that gradually with increasing knowledge more dawn songs of Tyrant flycatchers have been gathered. Obviously, the issue is that birds sing in near-darkness, and identification of the 'singing silhouette' is problematic, while singing may be limited to a short period in the year.

Dawn song of Central American birds is quite different from South-American birds:

Central American group (only dawn song of frantzii available, $n=6$ )

Dawn song is a repeated phrase "cheeh-rr-eéh...chee-rr-eéh...chee-rr-eéh..." (Fig. 1). This simple phrase consists of an overslurred whistle followed by a rising burry part and a higherpitched second overslurred note, all three notes interconnected without clear pause. As last note is higher-pitched, it sounds to the ear as if emphasis is on the last note.

1st note

$\begin{array}{ll}\text { min freq } 2800-3200 \mathrm{~Hz} \\ \text { max freq } & 4100-5000 \mathrm{~Hz} \\ \text { freq range } & 1300-1800 \mathrm{~Hz} \\ \text { length } & 0.09-0.11 \mathrm{~s}\end{array}$

2nd note

$\min$ freq $3700-4800 \mathrm{~Hz}$

max freq $\quad 5400-6200 \mathrm{~Hz}$

freq range $\quad 1300-1700 \mathrm{~Hz}$

length $\quad 0.09-0.11$

total length

$0.24-0.26 \mathrm{~s}$

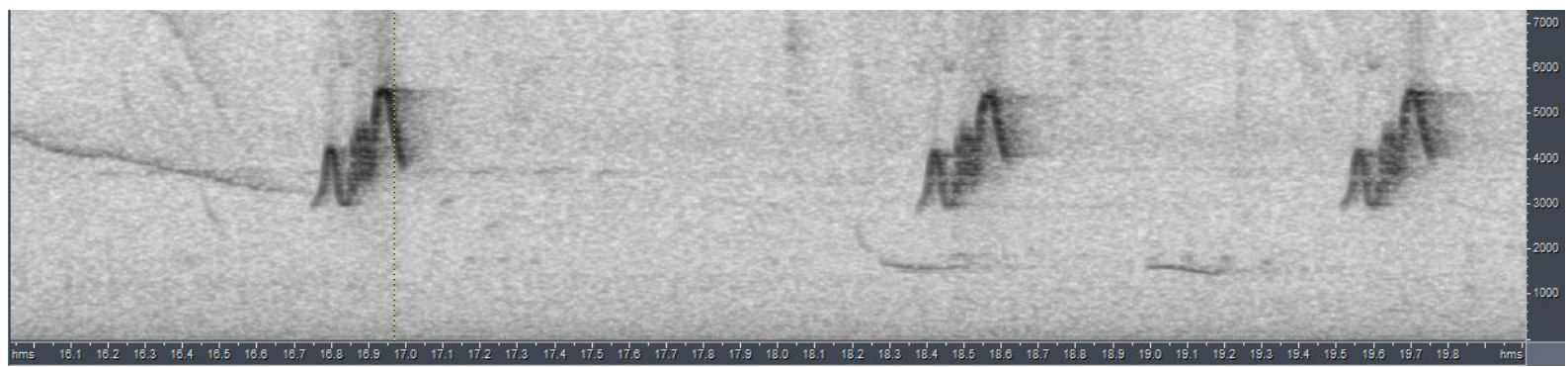

Figure 1: typical dawn song of race frantzi 

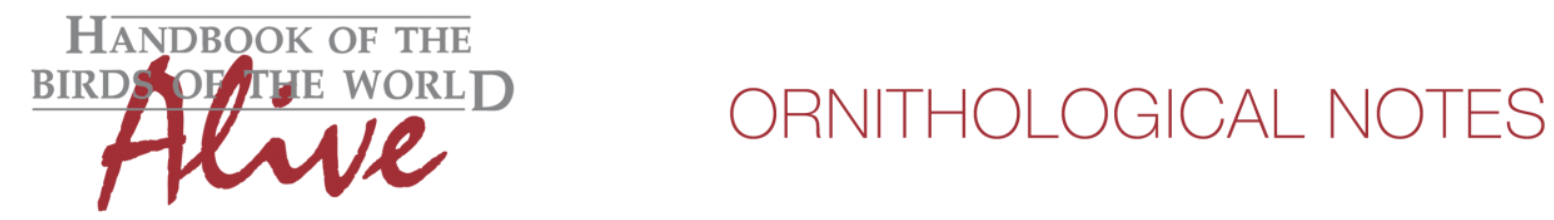

South American group (pudica and browni, $\mathrm{n}=11$ )

Dawn song is a combination of two phrase types. Phrase A "whéerr-heeh" consists of an overslurred note (sharp upside-down V-shape, with a burry descending leg) followed by a well-separated underslurred $V$-shaped note, both notes covering about the same frequency range (on a sonogram very different from previous group, Fig. 2). Also, sounds to the ear as if first note is emphasized, unlike previous group. Phrase B is identical to phrase $A$ but with the addition of a gurgling ending rattle "whéerr-heeh-brrrr". Phrases are typically uttered intermittently AABAABAAAB.. etc., occasionally only AAAA... or BBBB... (unlike in Central American birds, which seems to have only one single phrase $A$ )

1st note

$\begin{array}{ll}\text { min freq } 2200-2700 \mathrm{~Hz} \\ \text { max freq } & 5300-6200 \mathrm{~Hz} \\ \text { freq range } & 3000-4000 \mathrm{~Hz} \\ \text { length } & 0.16-0.22 \mathrm{~s}\end{array}$

2nd note

$\min$ freq $2450-3000 \mathrm{~Hz}$

max freq $\quad 5600-6300 \mathrm{~Hz}$

freq range $\quad 2700-3800 \mathrm{~Hz}$

length $\quad 0.075-0.11 \mathrm{~s}$

total length

$0.26-0.30 \mathrm{~s}$

ending gurgling part

$\min$ freq $400-700 \mathrm{~Hz}$

$\begin{array}{ll}\text { max freq } & 5000-6000 \mathrm{~Hz} \\ \text { length } & 0.14-0.16 \mathrm{~s} \\ \text { \# of notes } & 4-5\end{array}$

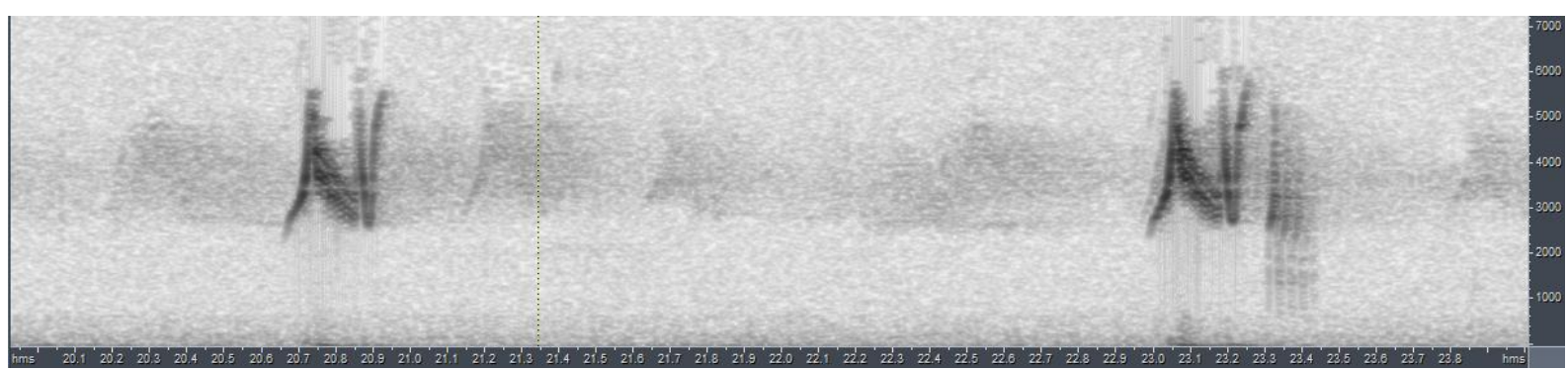

Figure 2: typical dawn song of South-American birds, illustrating a phrase A and a phrase B

Dawn song recordings of both groups are about identical within each group, and very different between both groups, and thus, assignment to one of the 2 groups on a sonogram is straightforward.

This can be quantified by e.g. pointing out that Central American group has a first note which is shorter (score 3 ) with a much smaller frequency range (score 3-4), a second note which is higher-pitched (score 3) with a similar smaller frequency range (score 3-4) and a total length which is slightly smaller. Central American group has only one phrase, while South-American group has 2 distinct phrases (score 3), the second phrase ending in a gurgling rattle with min. frequencies far lower than any frequency in Central American group (score 3-4).

Call notes seem to differ much less. One call type seems to be more drawn-out with flatter frequency slope in South-American groups, although there may be some overlap. A more in depth analysis would be needed to establish any diagnostic differences. 
Based on the very different dawn song (much more so than what appears to the human ear, due to the fast rendition of the phrase), by applying Tobias criteria, a total vocal score of about 6 can be given.

This note was finalized on 10th August 2015, using sound recordings available on-line at that moment. We would like to thank in particular the sound recordists who placed their recordings of dawns ong for this species on XC and ML: Peter Boesman, Jerome Fischer, Niels Krabbe, Dan Lane, Bernabe Lopez-Lanus, Curtis Marantz, Linda Macaulay, Alexandre Renaudier, David Ross and Paul Schwartz.

\section{References}

Tobias, J.A., Seddon, N., Spottiswoode, C.N., Pilgrim, J.D., Fishpool, L.D.C. \& Collar, N.J. (2010). Quantitative criteria for species delimitation. Ibis 152(4): 724-746.

\section{Recommended citation}

Boesman, P. (2016). Notes on the vocalizations of Mountain Elaenia (Elaenia frantzii). HBW Alive Ornithological Note 134. In: Handbook of the Birds of the World Alive. Lynx Edicions, Barcelona. (retrieved from http://www.hbw.com/node/932057 on 9 August 2016). 